\title{
Hemolytic anemia due to adenylate kinase deficiency
}

INSERM

\section{Source}

INSERM. (1999). Orphanet: an online rare disease and orphan drug data base. Hemolytic anemia due to adenylate kinase deficiency. ORPHA:86817

Hemolytic anemia due to adenylate kinase deficiency is a rare hemolytic anemia due to an erythrocyte nucleotide metabolism disorder characterized by moderate to severe chronic nonspherocytic hemolytic anemia that may require regular blood transfusions and/or splenectomy and may be associated with psychomotor impairment. 